\title{
Soldiers and 'respect' in complex conflicts: an Afghan case
}

\section{Cornelia Vikan}

Department of Philosophy and Religious Studies, NTNU Norwegian University of Science and Technology, cornelia.vikan@ntnu.no

DOI: http://dx.doi.org/10.5324/eip.v12i1.2258

(cc) BY

This is an open access article distributed under the terms of the Creative Commons Attribution 4.0 International License, which permits unrestricted use, distribution, and reproduction in any medium, provided the original author and source are credited.

This paper discusses the meaning of 'respect' in complex conflicts and aims to contribute to the thinking about ethics in war, along with the Just War tradition. The point of departure is the increased focus on soldiers as moral decision-makers in war, illustrated by the introduction of core values in the Norwegian Armed Forces. 'Respect' is one of these core values. However, it is not clear how we should understand respect in this kind of context. I use a case where a group of Norwegian soldiers in the International Security Assistance Force (ISAF) sought the cooperation of a group of mujahedeen to solve the military mission of establishing security. As confidence between the parties grew, the soldiers became horrified witnesses to a practice of bacha bazi, where a young boy is dressed up for entertainment and is sexually abused. I discuss different perspectives of respect in this specific context to show the importance of acknowledging the multitude of moral stakes in a moral decision-process instead of closing our eyes to a moral problem.

Keywords: war, respect, cultural practice, toleration, Just War Theory, Afghanistan

\section{Introduction}

Respect is one of three core values ${ }^{1}$ of the Norwegian Armed Forces (Forsvaret 2011, 2015a, 2015b). The core values were introduced a decade ago as part of the work to keep up a high ethical standard in the military profession, and they have since been an essential part of the ethical training of soldiers ${ }^{2}$. However, it is not clear what these core values mean in a complex war context. This paper is dedicated to exploring the meaning of respect as an ethical guideline for soldiers in a complex war context, where established ethical principles for war come up short and where soldiers must rely on their own capability in ethical judgment beyond existing rules. The purpose is to come to a better understanding of what is morally at stake for soldiers concerning respect in a context such as Afghanistan.

I use a specific case to illustrate different perspectives of respect, a case that I have also used in a paper on soldiers' responsibility ${ }^{3}$. This case depicts a so-called 'low intensity' context (Trettenes 2009) during the ISAF mission, where soldiers have the time and occasion to deliberate about the situation and figure out how to handle it. It is easy at first sight to see the need to understand respect in this multicultural 
context, where confidence building and cooperation are as essential as mastering traditional military skills. However, unexpected events in this case make it less clear what respect means or which perspective of respect to give priority to in the situation of moral choice that arises.

\section{Case description}

The situation described in this case was experienced by a task group of ISAF soldiers and lower rank officers (hereafter soldiers) in Afghanistan at the very beginning of the ISAF mission. Their task was to cover an information gap along a route where ISAF forces were to make important movements with personnel and equipment into new territory. A group of twenty to thirty mujahedeen soldiers controlled the route. They were heavily armed and controlled checkpoints where they claimed taxes from locals and transport companies. There were reports of kidnappings, but otherwise little was known about the group's loyalty, intentions, activity and conduct at the checkpoints. Their view on ISAF was not known, and there was uncertainty as to whether one could expect cooperation on security or whether the group itself represented a security threat to ISAF. The main effort for the ISAF soldiers was to build trust between themselves and the mujahedeen group.

The ISAF group succeeded in being invited to meet the leaders of the group. The meeting was a success. The ISAF soldiers had brought halal meat to share, the mujahedeen men were positively curious about the soldiers, the atmosphere was good, and the ISAF soldiers spent the night. On this first meeting, the ISAF group noticed a boy about ten or twelve years old, who served them tea and food. They were thinking that he might be an orphan of some relatives who was being taken care of by the group, which wasn't anything unusual.

Over time the ISAF soldiers and the mujahedeen leaders came to know each other well, so well in fact that they were able to joke about sexuality and women. The boy appeared every time, and several times now dressed up in women's clothes and makeup. He danced for the men, and the rest of the time he sat in a corner rocking back and forth. The men made hints about 'the little lady'. At one point, after yet another dinner meeting, the mujahedeen men asked the ISAF soldiers whether they would like 'to spend some time alone with the boy'. There was no hint of joking in their offer; it was rather more like a vote of confidence. The ISAF soldiers somehow managed to get out of the situation without offending the men, but from that point on it was clear to them that this young boy was more than a servant of the house. The ISAF soldiers perceived clear signs of psychological problems in the boy's behaviors, such as his stuttering, the catatonic rocking, no eye contact, his introvertedness, the dressing up, the way he performed, and the way he was treated and referred to by the mujahedeen men. The soldiers concluded that the boy probably was being raped on a regular basis by one or more of these Afghan men.

From the point when the ISAF soldiers knew about the boy's situation, they started to weigh the boy's future against the trust they had gained from the mujahedeen, and thereby the whole mission. The soldiers were seriously worried about the boy, and at the same time very conscious of the importance of their relationship to the mujahedeen group for the security of the ISAF in the area. 


\section{Discussion \\ A 'prima facie' approach}

The dilemma in the case above is indeed genuine in that it is not possible for the soldiers to cover the whole amount of possible moral responsibilities it represents. On the other hand, it does not seem like an insoluble dilemma, where soldiers cannot be expected to make morally sound judgments based on ethical decision procedures, and where the outcome of their choice becomes a matter of moral luck (Schulzke 2013: 95). On the contrary, I argue that the soldiers in the given case do implement a kind of ethical decision-making procedure by balancing competing duties and values. The following discussion shows that the act of balancing different duties associated with respect as soldiers and human beings, and the relationship between role and duties, are important. What kind of duty is associated with the boy? Can it be seen as part of the role as soldier to try to protect him? Or is it a more general duty, derived from the fact that they are in the same room with the boy and could do something? And does that change anything regarding respect? One way or the other, the soldiers need to make a decision. It will have practical consequences, and arguably some moral impact, but at some point they have to make a choice.

The principle of prima facie duties in medical ethics is a way of understanding this overall situation of having to balance competing duties. A prima facie duty is a moral duty at first appearance, but it is not an absolute one, since it needs to be balanced against other, and equally important, moral duties (Ross 1930) ${ }^{5}$. The fact that one has to choose one duty over the other does not mean that the other duties are set aside. They still are just as important, and still should leave 'moral traces' (Ruyter, Førde and Solbakk 2007).

In the same way, the soldiers in our case need to balance moral duties and perspectives and make a choice between these competing moral duties and between perspectives of respect. Their moral duty to take care of primary role obligations like security may seem like the more important moral duty at first sight, but the soldiers need to consider other moral duties. The moral outcome then is arguably not a matter of moral luck, but rather of intended and unintended effects of a moral choice. The practical effect of their choice cannot be guaranteed, so in this way luck does play a role. But the important moral matter is that contrary to Shulzke's insoluble dilemma, the soldiers in this case can be expected to make morally sound judgments. And even if the dilemma in its nature is unsolvable, it may be resolvable: it is possible to 'take it apart' to clarify the nature of the moral stakes.

Concerning the stakes, it is a fact that decisions are made at presumably high risk for the soldiers themselves and their mission, so a key word in the case is security. The context is also multicultural, putting to the test values like 'respect' and 'toleration'. Loyalty is also at stake in relation to other perspectives of respect.

Therefore, how can respect contribute to resolving the moral complexity in this case? First of all, what do the Norwegian Armed Forces mean by respect? The explanation given in the Armed Forces' Values and Standards will be my starting point.

\section{Respect as described by The Norwegian Armed Forces}

We must show respect for decisions and missions. Once a decision has been taken and a mission is to be carried out, we must comply with that decision 
and carry out the mission as best we can [...] Respect for decisions and missions is enhanced when superior officers listen to advice and comments from their subordinates and from other parts of the organization (Forsvaret 2015b).

Between the lines in these quotes, there is an awareness of unexpected situations that happen in every part of the service, including international operations. Accordingly, there must be room for deliberation. However, the more important premise for this discussion is the understanding that respect is tantamount to loyalty once a decision has been taken. This is respect for authority (Dillon 2015). Respect for authority defines the role of the soldier, and loyalty to role obligations is, as mentioned, at stake in our case when the soldiers are left to their own judgment. Respect for authority also includes respect for 'the rules of the game', that is the rules to play by in war: international law, international humanitarian law, Human Rights. If we also include respect for authority as respect for one's own autonomy as moral decision-maker - a recognition of the authority in oneself, there may be a need to balance these authority perspectives. In the description of respect, we also find that respect is a moral duty:

Respect is not a right; it is a moral duty that is expressed in attitudes and actions. Respect builds upon self-respect. Self-respect gives a person the strength to stand upright in difficult situations. Self-respect is reinforced through a conscious pattern of behavior based on ethical principles, doing your best to do the right thing. In the Armed Forces, we are all expected to show respect for one another, for our colleagues, for our superiors and for our subordinates. In difficult situations, when living in cramped conditions, our ability to treat others with respect will be tested. The key indicator in all situations is whether we treat others as we expect to be treated ourselves (Forsvaret 2015b).

Thus, respect is a moral duty, which is based on self-respect, and the importance of respecting others, the 'respect for persons', is emphasized. These are perspectives we need to look into. My point of departure is Kant's account of respect as acknowledgment of a person's dignity as ends in themselves. Charles Taylor's account of 'recognition respect', which is dialogically established, is also relevant for the present case, as it is not quite clear what 'showing respect' and 'respecting others' means (Taylor 1994).

Kant's idea that self-respect is a moral duty and the basis for all respect can be contrasted with Rawls' account of self-respect as a social good. Both accounts have some relevance in our case, as I will show. In addition, the idea that self-respect according to the Norwegian Armed Forces' description is supposed to be reinforced by striving 'to do the right thing' raises a series of questions related to self-respect. How strongly is self-respect associated with role obligations, and how strongly is it associated with other important obligations? Is the fulfillment of primary role obligations a substitute for self-respect? I will discuss these questions in due course. The description of respect continues:

The Norwegian Armed Forces will not accept any form of racism or inhuman, degrading or disrespectful treatment of others. Sexual harassment is likewise unacceptable. Armed Forces personnel are to show respect for the fundamental values and cultural traditions of the area in which they are operating (Forsvaret 2015b). 
The multicultural context of our case makes 'respect and culture' an issue. However, I want to stress that the main reason to include this perspective in the discussion of respect in our case is the importance of demonstrating what culture is not. The relationship between respect and toleration will be part of this discussion. What does zero toleration of sexual harassment and 'inhuman, degrading, and disrespectful treatment of others' look like in our case? I will look at how toleration is distinct from respect and how it sometimes can be almost the same as respect. I aim to demonstrate how important it is to be aware that not everything can be respected, and not everything that somebody calls culture should be tolerated. It is therefore important to show how little 'respect for culture' adds to this case: it is tempting to say that the bacha bazi practice is about culture, implying that it has a claim to respect, but this would be a big mistake, as I shall argue.

Another kind of respect, which is not a moral kind of respect, is important to note in the case. It is called 'responsive respect'. This is an object-generated kind of respect, like the respect we have for an adversary, for instance because he can be dangerous, not because he is a good or bad person. Thus, responsive respect is different from recognition respect in not being morally founded. I intend to show that in our case, responsive respect in fact seems to overrule recognition respect which for its part seems to be compromised, and I will therefore include it in the discussion.

Finally, the question of moral injury is important to mention, because moral injury is associated with experiences that can be damaging for self-respect. Moral injury is defined as 'perpetrating, failing to prevent, bearing witness to, or learning about acts that transgress deeply held moral beliefs and expectations' (Litz et al. 2009, in Maguen and Litz 2012). Symptoms of moral injury according to studies cited in the above-mentioned article (Maguen and Litz 2012) include selfdeprecation.

Based on the Norwegian Armed Forces' presentation of respect, my discussion will now revolve around the different perspectives mentioned above: 'recognition respect', 'respect for authority' and 'rules of the game', 'respect and culture', 'respect and toleration' and 'self-respect'. In addition I will discuss 'responsive respect' and the question of moral injury. Throughout the discussion, I aim to demonstrate how the real dilemma is about balancing different perspectives of respect and different obligations as soldier and human being. Overall, I aim to demonstrate the importance of recognizing the need to do so.

\section{Recognition respect for persons}

There is a tension between respect for persons as individuals on the one hand and respect for persons as members of a collective on the other in this case. This tension can be found in the dialogical context of developing identity. A fundamental dialogical character of human life is what connects identity and recognition, a point Charles Taylor made in his essay "The Politics of Recognition" (Taylor 1994). This means that in our process of defining ourselves we acquire the languages we need through interaction with others who matter to us (Taylor 1994). Taylor's account is compatible with the way our soldiers have developed their identity as persons, and at the same time how they identify themselves according to their role context as soldiers. Group belonging matters strongly in the development of military identity and attitude. As soldiers, they thus have a collective identity, and the individual 
loyalty belongs to the members of the collective. In this case, the recognition of the collective comes into conflict with recognition for other individuals: should they give more weight to their group loyalty and security and ignore the abuse of the boy, or should they recognize the boy and the mujahedeen men by telling the men that the bacha bazi practice is unacceptable? In a dialogical perspective of recognition respect the question is whether it is possible to recognize the boy and the mujahedeen men by not confronting the men.

Kant held respect as something truly intrinsic to being a person: the basis for moral duty. When we meet other people with respect, it means we recognize the fact that they are rational beings with dignity, capable of moral agency, even if some people fail to live up to their own dignity. Even the worst criminal, like the child rapists in this case, have their own dignity, according to Kant (Dillon 2015). In meeting people, we recognize them as persons, because persons have intrinsic worth as ends in themselves, and that requires a certain attitude and agency. Many writers have followed Kant and contributed to the concept of recognition respect. Darwall writes that recognition respect is respect for a person just by virtue of a person being a person (Darwall 1977). Darwall's recognition respect follows the line of Kant's respect for persons as ends in themselves. According to Darwall, the attitude and agency required are shown by "giving appropriate weight to the fact that he or she is a person by being willing to constrain one's behavior in ways required by that fact" (Darwall 1977: 45). The soldiers' behavior towards the men can thus be seen as the basic respect for persons according to Darwall's line of thought.

This makes some sense in our case, at least to a certain point. On the other hand, Darwall does not specify what constraining ones behavior "in ways required" by certain facts really means. I suggest it means paying special attention as one would do if respect were a kind of prima facie duty (Beauchamp 1994; Ross 1930; Ruyter and others 2007). With the prima facie duties then, one has to constrain one's behavior at first, in the same way as Darwall demands constrained behavior from recognition respect. Thus, as mentioned earlier, various perspectives of respect could be seen as different prima facie duties, which have to be balanced against each other in reaching a final judgment.

Concerning the requirement to express recognition respect, this could then imply that one primarily constrains one's behavior towards other people and takes time to reason and weigh alternatives before acting. This is what the soldiers seem to do if we apply such an understanding of recognition respect: even when they find out about the men's bacha bazi practice, the soldiers continue to constrain their behavior towards the men as before. However, they also constrain their behavior towards the boy. Is the soldiers' passive behavior, in a situation where they are aware that their interlocutors are committing a serious crime, really recognition respect? Something in Darwall's account of recognition respect seems inadequate in this case after all.

His account for recognition respect seems to be relevant only to a certain point, but it becomes insufficient when the facts about the bacha bazi practice are revealed. The reason why is the puzzle of how one can regulate one's behavior the way the soldiers do as a way of showing recognition respect when the persons entitled to recognition respect harm a child the way they do. That might look like showing respect for the mujahedeen, but I suggest the soldiers' conduct rather comes from a 
kind of responsive respect, not a respect for persons. I will return to this point shortly.

It follows therefore that Darwall's account does not add sufficient understanding to recognition respect in this case. Following Kant, on the other hand, the men are still entitled to recognition respect, since they are still persons with their own dignity, even if they fail to live up to it. But I suggest that recognition respect towards the men requires a different way of behaving than the soldiers show. The soldiers seem not to want to confront the men out of their concern for the practical consequences it might have for security, which is incompatible with recognition respect in this case as I will show below.

Respect for persons appears to be absent. As soon as the soldiers become aware of the bacha bazi practice, their apparent respect appears not to be genuine anymore. From then on, it looks like the foundational recognition respect is compromised. Taylor points out that Kant's use of the term dignity has been central for our intuitions of equal dignity, and that there is a universal, human potential that makes each person deserve respect (Taylor 1994). In line with this idea, as Taylor argues, recognition is important for the shaping of our identities, both at an intimate level and a social level, and this recognition is established in the dialogical struggle with significant others. Dialogue is a central concept here, and in this dynamic struggle to shape identity, the power of recognition lies both in actively engaging other persons and in being engaged. I read Taylor's account as also meaning that the recognition of the universal potential of dignity lies in engaging with other persons. Adeno Addis (1997) states similarly that to treat persons and their way of life with respect means to engage them, not to treat them as strange or alien (Addis 1997). Looking at recognition respect this way makes more sense in the context of our case. We see that the soldiers fail in recognizing the men by not engaging them in what they think about their practice. Engaging the men in dialogue would be to recognize their potential for human dignity, per Taylor's account. And according to him, recognition can also fail.

To summarize, Darwall's account of recognition respect as restraining one's behavior fails at some point. Taylor's account of recognition as dialogically established - and following from that a requirement to continue to engage with persons - works to explain a lack of recognition respect in the case. If the soldiers' behavior represents any kind of respect, it is not a morally founded one. In fact, the situation calls upon the literal meaning of respect, the need to look again, and I will now turn to another important perspective in the case mentioned above, the 'respect for authority'.

\section{Respect for authority and the rules of the game}

Respect and authority are linked by the idea that authority is something that must be reckoned with (Bird 2004: 213). Colin Bird has suggested criteria for what makes something 'reckon-worthy', that is, exerting 'an independent and recognizable normative force with which deliberating agents must "reckon"' (Bird 2004: 212). Bird's example is directly applicable to our case: 'A valid command issued by an authority is not simply something I can dismiss as of no importance - I must recognize the claim it makes upon me and reckon with it, even if I decide eventually to disobey' (Bird 2004: 213). There is a link back to Kant. Bird points out that Kant's view of persons as self-legislators 'just is to recognize a kind of authority that they 
bear' (Bird 2004: 213). For the soldiers in our case this would mean that there is a tension between the soldiers' authority in moral decision-making and the respect for authority imposed by the system.

The soldiers' concern about security as part of their role and their respect for role obligations is in other words respect for authority. Role obligations are understandably the first and foremost guide in situations where soldiers' judgments are made under a great deal of uncertainty. The case discussed here is no exception. There is great uncertainty about the outcome of the situation either way the soldiers choose to act. One decision may be fatal for the soldiers, the mission and/or the boy in a worst-case scenario. A different decision may save the mission, but compromise other important perspectives. If we apply the principle of prima facie duties mentioned earlier, we must balance different perspectives of respect against each other. If it is not possible to meet the requirement of all perspectives, we must give more weight to one perspective. As already stated, it does not mean that the other perspectives of respect are less important. This is something that the soldiers have to deal with. Their role obligations, which are authoritative, help them navigate. They are primarily soldiers on a mission, with a specific task to carry out. Ingierd (2007) points out the special obligation for commanders at all levels to minimize risk for their own soldiers and not to expose them to unnecessary dangers (Ingierd 2007). The same attitude presumably applies among the soldiers themselves. Throughout their education and service, soldiers in the Norwegian Armed Forces develop a strong loyalty to their fellow soldiers and the system of which they are a part. We see this reflected in the description of respect in the Armed Forces' Values and standards (Forsvaret 2011, 2015a, 2015b). Soldiers' informed actions would therefore naturally be strongly influenced by their loyalty to professional obligations.

As argued, what the soldiers show vis-à-vis the mujahedeen men cannot be recognition respect according to Taylor (1994) or Darwall (1977). Their behavior is rather rooted in the respect for authority as expressed by the soldiers' mission and orders, and their role obligations. The soldiers' respect for authority does not compete with their sense of respect for each other as a group. These perspectives together rather seem to compete with recognition respect for the mujahedeen and the boy.

Another perspective of respect associated with authority is, as mentioned, the respect for the 'rules of the game', which needs to be addressed. The Geneva Conventions constitute the core of the international humanitarian law (IHL) (ICRC 2016), and the UN Convention on Human Rights (HR) (UnitedNations 1948, 1989) makes it possible to discuss respect with reference to a formal, minimum concept of shared standards across cultural differences. Both Norway and Afghanistan have signed the conventions. These rules of the game also constitute an authority that the soldiers must reckon with in their judgment and decision-making. In this case, not only the mujahedeen men, but also the soldiers appear to ignore respect for these rules when it comes to the treatment of the boy. This is a dilemma: respect for role obligations competes with respect for human rights that are violated before their eyes. All their concerns about security limit the soldiers, at the same time as the practice they witness is unacceptable. It is morally right to stay loyal to their role obligations in a situation of extreme uncertainty. At the same time, it is morally right to intervene when somebody's autonomy is seriously harmed. Again, it looks 
like a prima facie situation, this time between competing moral duties as such: no one action is more morally right than the other as a prima facie duty. In other words: it would be morally wrong to take too high risks at the cost of security concerns and professional duty, and it is likewise morally wrong not to do anything to protect the boy. The question is what kind of duty the soldiers have towards the boy: is it a duty per se because they happen to be close to the situation and thus can do something about it? Or is it part of their role obligations as soldiers with reference to their mission of securing and stabilizing, including protecting the Afghan people ${ }^{6}$, but a weaker obligation than the obligation to safeguard their own security?

Their judgment seems to favor their professional obligations to the security situation, which leaves them with a sad paradox: they end up not being able to protect one of the Afghan people, which was the rationale for the soldiers being there in the first place. It turns out that sometimes respecting important duties implies not respecting other, and competing, moral duties. Even worse in this case, sometimes respecting role obligations means tolerating unacceptable practices. Yet knowing this is different from not respecting the situation as such by hastily grasping for role limits to 'solve' the dilemma. The difference is important, not because knowing means we are free from moral culpability in a situation (Ingierd and Syse 2005), but because knowing means we are persons capable of seeing things as they are. Knowing the moral difference, in other words, maintains an important ethical standard.

\section{Respect and culture}

I will now shift attention to the multicultural context and the challenges this fact poses to the understanding of respect. The term 'culture' is notoriously difficult to grapple with, and it is not my purpose to explore culture as such. My purpose is to show what culture is not, and that culture cannot be a moral justification for unacceptable practices. Respect and culture are linked by the idea that respect for persons, or recognition respect, includes respect for the culture these persons represent (Addis 1997). I argue that such a linkage between culture and respect is not always legitimate. There are unacceptable practices that are not part of culture with a claim to respect. Likewise, not everything that somebody calls culture has a claim to respect. The word culture does not emerge in the present case description, but in a very similar case, bacha bazi is indeed referred to as part of culture. In that particular case, an American soldier told his superior that their Afghan cooperation partners practiced bacha bazi. The soldier in turn was told by his superior to ignore the practice as part of the culture (Goldstein 2015). In other words, culture was used to justify non-intervention. The soldier was told to close his eyes, as if ignoring the practice were equal to respect for people and their culture. Instead we should be much more careful with reference to culture. In the words of Taylor (1994):

It makes sense to demand as a matter of right that we approach the study of certain cultures with a presumption of their value...but it can't make sense to demand as a matter of right that we come up with a final concluding judgment that their value is great, or equal to others (Taylor 1994: 68-69).

Similarly in our case, the practice cannot be seen as part of culture, and the soldiers' non-intervention cannot be seen as based on respect, as if it is possible to respect an unacceptable practice. And even if recognition respect includes, according to some 
writers, respecting the culture and traditions of people and their society (Addis 1997; Dillon 2015), this view is compatible with cultural relativism and can be taken too far.

In a dialogical perspective of respect, it is a point that not all Afghans agree with the bacha bazi practice, and that the greater Afghan society rejects the practice by $\mathrm{law}^{7}$. The soldiers, being there on a government-assigned military mission to stabilize the security situation, are for their part witnessing this crime without trying to intervene. However, respect for persons as reflected in human rights is a guide to more clearly see the moral stakes. The multicultural landscape is a challenge to navigate, and the question of respect is sometimes hard to distinguish from the question of toleration. It is thus important to better understand the relationship between respect and toleration, which I will turn to next.

\section{Respect and toleration}

In the essay "On Human Diversity and The Limits of Toleration", Adeno Addis (1997) writes that there are positive and negative definitions of toleration.

To tolerate is not necessarily to respect, we could call this paternalistic toleration, which is based on indifference or accompanied by non-respect. On the other hand, to treat individuals with "equal respect" entails, at least partly, respecting their traditions and cultures, the forms of life which give depth and coherence to their identities, which means to engage those lives, not simply to tolerate them as strange and alien (Addis 1997: 121).

A closer look at toleration helps to reveal what moral compromises the soldiers make for staying loyal to their role and mission. Addis' description is introduced in a different context, but is useful in stressing the main point: respect is everything but indifference, but toleration can be indifference. The soldiers in our case are not indifferent to the practice they witness; yet for all practical purposes they seem to tolerate it. Unlike the soldier in the American case, they are not explicitly told to tolerate, but they choose to. Their role obligations seem to be stronger than their willingness to risk compromising them. I will come back to this point shortly.

We know that the soldiers are concerned and discuss what to do. How can we say that they tolerate the practice? One reason is that toleration requires the tolerating person not to intervene in the deviance of the holder of the intolerable opinions and actions (Khomyakov 2013). Our case reveals what Khomyakov calls the paradox of toleration: how can one consider something to be morally right that includes accepting what one perceives as morally wrong? Khomyakov puts it even more pointedly when he states that 'the principle of toleration calls upon us to tolerate the intolerable' (Khomyakov 2013: 225, quoting Heyd 2003). Then Khomyakov also states that by thinking that something is morally wrong, one is committed to fighting it (Khomyakov 2013: 225), which is interesting in light of recognition defined as engaging with people. It means that out of respect for the mujahedeen men and out of non-toleration of the child abuse, the soldiers could fight the child abuse by telling the men what they think.

Toleration does have the positive aspect that people are able to preserve a great sense of liberty. Khomyakov points out in Mill's On Liberty that toleration is itself a dimension or an aspect of liberty (Khomyakov 2013: 231). It means that we are obliged to tolerate all opinions or actions of an individual we dislike or disapprove of. But note that this is true only as long as this individual does not harm other 
people (Kukhatas 1997). So the flip side of liberty is naturally that it can be abused, which is something we should not accept. Kukhatas (1997) describes the limits of cultural toleration in a similar way. His account and Taylor's account that not everything merits respect - or toleration, implying respect - evokes the significant harm principle. A lot of things can be tolerated as long as they do not involve significant harm to other people. In the same way, tolerating the mujahedeen men's abuse of the boy in itself requires accepting the abuse, which is wrong.

Knowing about the soldiers' pain in discussing the dilemma back and forth, it seems wrong to say that they accept the child abuse. But if their non-interference is not toleration, what is it? It seems more accurate to say that they do not accept the moral rightness of the practice and are thus committed to intervening, in line with Khomyakov's account, but they fail to do so. They face a dilemma of competing moral and professional obligations. And they tolerate, not out of indifference, or acceptance, but out of competing perspectives.

The limits of toleration are indeed hard to grasp. Whether it is possible to tolerate something one does not accept, or whether toleration involves accepting, remains a pending question. In our case we can use the word toleration because it is apparently accompanied by non-respect (Addis above). The bottom line seems to be that toleration of the harm done to the boy is what the soldiers pay for being loyal to their role obligations. This possibility stems from 'respect for authority' and in addition, responsive respect for the mujahedeen, which I will investigate next.

\section{Responsive respect}

Responsive respect is a kind of respect that has no element of right or wrong. The literal meaning of respect, derived from Latin respicere, means 'to look back at' or 'to look again' (Dillon 2015). The meaning is similar to 'paying attention', so in general terms, when we respect something we accept its call to our attention. Respect is then object-generated, and there are thus many objects that can be respected for different reasons, which Dillon outlines (Dillon 2015). Responsive respect means that we respect not because of the intrinsic worth of something or someone, but due to other factors. Dillon points out four different traits of such 'responsive respect': (1) we respond to it as something whose significance is independent of us, (2) we experience the object as something constraining our attitudes and actions, (3) we logically have to assume that our own reasons for respecting the object are also other people's reasons to respect the same object, thus this kind of respect is impersonal, and (4) respect is universalizing (Dillon 2015: 8), that is, if the soldiers have reasons to respect this group of mujahedeen men, they have reasons to respect other groups of mujahedeen men too.

In our case, the mujahedeen men can be respected in this way for being potential adversaries, for instance. They merit respect because they are potentially dangerous and powerful, and this fact requires a certain way of behaving towards them. The respect may involve fear, honour, self-protection and other ways of responding to the object, in this case the mujahedeen. Respect for authority and responsive respect in combination are stronger motivations for the soldiers than the motivation to intervene. The result is that the soldiers commit an act of omission towards their own moral standards and the common standards of human rights. 
The ethical question in this case is to what degree the soldiers can compromise their loyalty to role obligations and their respect for the mujahedeen men as potential enemies.

With these competing perspectives of respect, the respect for authority and responsive respect for the mujahedeen as partners and potential enemies seem to overrule recognition respect for the men and the boy. Since recognition respect seems to be compromised, it is necessary to go back to the Norwegian Armed Forces' description of respect, according to which the basis for respect is selfrespect. Self-respect is therefore important to address next.

\section{Self-respect}

In the Norwegian Armed Forces' Values and Standards, the importance of selfrespect is acknowledged by stating that 'self-respect gives a person the strength to stand upright in difficult situations', and is 'reinforced through a conscious pattern of behavior based on ethical principles, doing your best to do the right thing' (Forsvaret 2015b). Self-respect then is what helps us stand upright. What can a conscious pattern of behavior based on ethical principles that are supposed to reinforce self-respect mean? There appears to be an interdependency between respect and self-respect, although it is not clear exactly how we should understand it in our specific context.

Thus, concerning our case, how might tolerating the gross violations of human rights affect the soldiers' self-respect? On the other hand, is it necessary for the soldiers to pay attention to human rights and their professional duties at the same time to preserve self-respect? What perspective of respect is more important for selfrespect in this case? Again, the purpose is not to come up with the correct answer, but to show how respect and self-respect are linked in this case.

Self-respect consists of many things according to some theorists, but as a start we can take as a premise that self-respect is essential in our everyday lives, as Dillon (2015) concludes in his article on respect (Dillon 2015). Self-respect is considered to be both required and important in order to lead a meaningful, flourishing life, in fact a life worth living. To tell someone that he does not have self-respect therefore is a serious moral criticism (Dillon 2015). Dillon points out as important that selfrespect is vital to the quality of our lives together. There is also agreement that different kinds of self-respect exist, similar to the way several kinds of respect exist. In western tradition the concept is strongly related to self-value of two types: socalled status worth, or 'recognition self-respect', of which Kant's dignity is one form, and acquired worth, or 'evaluative self-respect', which is based on the quality of one's character and conduct (Dillon 2015: 42).

When we talk about self-respect as the foundation for respect, we are referring to recognition self-respect. This builds on Kant's argument that self-respect is the most important moral duty, without which there can be no other moral duties. Kant holds that we have specific duties to ourselves generated by the general duty to respect humanity in persons as rational beings with dignity.

Kant's dominant conception of persons grounds dignity in three things equality, agency and individuality. We can further distinguish three kinds of recognition self-respect (Dillon 2015: 43), which are: 1) "respect for oneself as a person among persons, as a member of the moral community with a status and dignity equal to every other person" (Dillon 2015: 43). Thinking of oneself as having 
certain moral rights that others ought not to violate is part of this kind of selfrespect; 2) appreciation of oneself as a moral agent who takes her responsibilities seriously; 3) an "appreciation of the importance of being autonomously selfdefining", that is living in a way one regards as worthy of oneself (Dillon 2015). To these three Kantian forms of self-respect Dillon points out a fourth, which is about respecting oneself as a concrete person, someone with social positions and thereby responsibilities that one needs to meet to be self-respecting (Dillon 2015: 4.1, citing Middleton 2006).

Kant's account of self-respect and thoughts derived from his works on respect add adequate understanding to self-respect in our case, as does the fourth kind of self-respect mentioned above. The soldiers have moral considerations beyond the limits of their role, which are due to their general moral standards and part of what constitutes their self-respect as persons. It means a person with self-respect will try to live up to these standards.

Self-esteem is different from self-respect in that it is not connected to moral standards. Thus a soldier may think he is a good sniper, because he has the professional skills required, but it does not mean he thinks that he is a good soldier or a good person. At the same time, the soldier's role is associated with certain moral requirements that are connected to self-respect. What matters in this case are the recognition self-respect and perspectives of such self-respect that are at stake and possibly compromised.

It can first of all be argued that self-respect is compromised by failing to live up to the moral standards of intervening in an intolerable situation in order to protect the boy from harm. At the same time, the soldiers refuse the offer from the mujahedeen to actively take part in the crime. They judge it too risky to confront the men, but they refuse the offer. The perspective of self-respect as appreciation of oneself as autonomously self-defining is particularly at stake, but they manage to live by their standards at this point. This experience also gives the soldiers a chance to appreciate themselves as moral agents, which is important for self-respect.

The fourth mentioned perspective of recognition self-respect is important in the case: the soldiers as concrete persons, with the social status of soldier, have responsibilities related to this status that they need to meet to be self-respecting. It is true that they are especially attentive to their role obligations. Again, the problem is that associated with their professional obligations is also the general obligation to protect the Afghan people, and they fail in trying to protect the most vulnerable category of people, a child. This occurs not in the sense that they make an effort to protect him and fail, but in the sense that they do not make any effort. In other words, their specific task is such that according to their own best judgment, they must compromise the overall idea of the mission at that point. In a combat situation the soldiers' duty to protect is easy to see as part of their duty to discriminate between combatants and non-combatants. It would in principle be a situation that does not leave the soldiers with a choice between competing moral perspectives (although other dilemmas may need to be grappled with).

By contrast in our low intensity context case, this boy just happens to turn up as a victim of child abuse committed by the soldiers' interlocutors. Self-respect then becomes more complex and difficult to understand than when looking at the importance of responsibilities related to social status as soldier. The fact that the 
soldiers had different feelings and opinions among them before they decided what to do shows how complex this challenge is.

\section{Self-respect as a primary good}

Another influential line of thought concerning self-respect is self-respect as a social good. This perspective gives us a link to the question of war veterans and moral injury, which is why I want to include it here. The idea comes from Rawls, who in contrast to Kant argues that self-respect is 'a primary good' and a 'social good', a merit, just like all other goods. He holds that self-respect is dependent on the political and social circumstances we live in, and accordingly, political and social institutions should be designed in such a way so as to not humiliate people. So selfrespect comes from the way people are treated by these structures. Many theorists have echoed Rawls' ideas, the main point being that self-respect is dependent on the recognition of others (Dillon 2015). This perspective is relevant to what may influence the soldiers' self-respect.

During the above discussion I have identified self-respect as a duty in the case, both as aspects of recognition self-respect and as someone with position and status with responsibilities to meet to be self-respecting. I suggest that the soldiers' selfrespect also might be dependent on how they are met and recognized by persons that matter to them, and by the military institution and the social and political structures they live in. If recognition by others is important for self-respect, one needs to be aware that lack of such recognition can damage self-respect. To conclude, if self-respect is linked to the soldiers' responsibilities in achieving their primary task to gather information and build confidence with shareholders of power in the area, resorting to these primary role obligations would be compatible with preserving an important kind of recognition self-respect. But other perspectives of self-respect will nonetheless be at stake.

There is also still a risk that respect for role limits become a crutch in some situations. Referring to role limits without giving the situation due consideration is tempting. There is always a possibility in morally challenging situations to simply say: 'That's not our job' (Vikan 2009: 38, translation by author), and it is possible for role reference alone to become a sufficient justification in moral decision-making. A way to handle the moral dilemma along these lines could indeed be to say, with no further consideration: 'It is not our job to consider the welfare of this boy, it is beyond our task'. This is a dangerous approach to take, potentially leading to laziness in moral judgment, and so it is incompatible with keeping up an ethical standard.

Without attempting to guess at the possible damage of self-respect in this case, loss or damage of self-respect is an implicit risk in compromising important moral standards. The main reason to consider perspectives of self-respect is indeed the fear of soldier demoralization ${ }^{8}$.

Even if the soldiers' respect for authority and role obligations is legitimate, it does not necessarily mean that their self-respect does not suffer from knowing that they failed to live up to other important, moral obligations as moral agents and persons. In other words, even if their choice was made after serious consideration on moral grounds, it does not mean that failing to fight the moral wrongness in the child abuse did not matter for their self-respect. It simply means they made a choice, and 
that the de facto toleration of other people's child abuse is something they have to live with.

\section{A closer examination of moral injury}

As stated, a decision of non-interference changes nothing in practical terms, but there is a moral difference in the way the soldiers consider different perspectives once they know what's going on. At the same time they may be morally culpable for not interfering. They are also, as mentioned, arguably not acting on their duty as ISAF soldiers to protect people in Afghanistan - even if it in the end is a weaker duty in this case.

The question of moral culpability is associated with the soldiers' omission to make an effort to stop the harm done to the boy. This is a general statement, not specifically concerning respect, but still valid in light of respect, as much as it is valid in light of other moral reasons and guidelines leading the soldiers to choose as they did. I include it, because the risk of moral injury is the possible effect of standing in this kind of moral dilemma and trying to make ethically sound judgments, which in turn leads to the question of how we meet veterans in dealing with their moral injury.

Soldiers, as decision-makers, can carry responsibility for crimes of war done by themselves or done by other soldiers, if they know about the crimes and do not interfere (Ingierd and Syse 2005). The same principle is relevant in our case. Even if other people than fellow soldiers are committing the crime in this case, the soldiers as decision-makers risk turning themselves into moral accomplices by not interfering. The fact that the soldiers abstained from taking part in the crime themselves therefore does not completely free them of moral culpability, according to Ingierd and Syse. There may be good, legitimate reasons not to intervene, but the point is that soldiers need to know what they risk morally, and that they risk becoming morally culpable of something they morally condemn. If they are not conscious of this risk, they may already have become demoralized. So again, the moral difference is to acknowledge the moral risks instead of closing one's eyes to the moral problem.

On the other hand, by compromising respect for the mujahedeen men, the soldiers - by their own best judgment - do not risk compromising security, and in this way they stay safely within the presumed limits of their obligations as soldiers. But we don't know whether or not telling the mujahedeen that their practice is wrong is less of a risk for the security situation than if the soldiers told them. The point is that when judgments and decisions are made under such extreme uncertainty, the rule is to act on the principle of 'better safe than sorry'. The security question is a key premise for the discussion, but even so, the American case mentioned earlier illustrates the uncertainty of any presumption concerning security: the soldier who was told by his superior to ignore the practice was soon after killed by a young boy in the apartment building who was himself a victim of bacha bazi (Goldstein 2015). Thus, not interfering can certainly also be risky with regard to security. It can in fact be very dangerous.

Despite the differences between the cases, decisions in both were made on presumptions of a worst-case scenario where security for their own troops would be compromised. In the American case - as far as we know - the security question was not a stated issue. In the Norwegian case the worst-case scenario for the soldiers 
would be to compromise both their own immediate security and to create a less stable security situation in general by tearing down the trust they were trying to build up. The soldiers chose the presumably less risky way of handling the situation. If the duty to protect the child in this case is not seen as part of the overall professional duty, but as a general duty as human beings simply because they happened to be there, protecting the child is outside their primary role and responsibility as soldiers. The duty to protect the child is still there, but it is a weaker duty than the respect for primary role obligations concerning security.

\section{Conclusion}

I have addressed the importance of clarifying the moral complexity in a modern war context concerning the meaning of respect. The analysis emphasizes the importance of the soldiers' capability in making important distinctions between perspectives of respect on the one hand and toleration of intolerable practices on the other. Soldiers need to be clear about the difference, because linking condemnable practices to culture as something to respect is an easy way to close one's eyes to these practices. The soldiers in the case I have used here have to choose between competing obligations regarding respect, where some obligations are integrated into the role of the soldier and other obligations are more general. This creates a situation that challenges their role. I have suggested the principle of prima facie duties as a possible approach to this moral complexity concerning respect. In this case, it means not taking for granted that one perspective of respect is more important than the other. Thus, a non-moral perspective of respect, like responsive respect for the mujahedeen, favors a certain practical solution, which also has moral sides to it: the moral duty to take care of role obligations concerning security. On the other hand, this choice of action results in not prioritizing another, equally important perspective of respect, that of recognition respect for persons and for human rights. Hence, in reaching necessary decisions, it is important that soldiers are able to make such autonomous judgments.

The focus in the military should be to keep up an ethical standard by acknowledging what is morally at stake. This implies an awareness that relying on role obligations alone is not sufficient justification for a moral choice without considering the moral compromises it involves. Likewise, acknowledging the moral stakes implies not using irrelevant concepts, such as culture, to justify unacceptable practices. Instead, it is important to see the unacceptable practices and accept the moral compromises that follow from having to choose between competing moral obligations.

\section{Notes}

${ }^{1}$ The Norwegian Armed Forces in 2006 chose respect, responsibility and courage (RAM) to be their core values. These core values are meant to be integrated in all of the activity of the Armed Forces at all levels, collectively and individually.

${ }^{2}$ For simplicity I will use 'soldiers' for both officers and soldiers, since the core values are applicable to all individuals of all ranks in the Norwegian Armed Forces, and since leadership is essential to soldiers and officers alike. 
${ }^{3}$ The paper "The meaning of responsibility in complex conflict: an Afghan case" is forthcoming in The Journal of Military Ethics, Taylor \& Francis. The case is based on an authentic experience. One of the soldiers involved conveyed it to me, and has verified my description for authenticity.

${ }^{4}$ The practice of "bacha bazi" - literally "boys for play" is an illegal, but common, practice in Afghanistan. These boys, orphans or boys from poor families, are sold to powerful men to dance/entertain and are often sexually abused by these men. The practice is also referred to as 'dancing boys' or 'tea boys'. See for instance http://www.pbs.org/wgbh/pages/frontline/dancingboys/etc/synopsis.html (20th April 2010, retrieved 22th June 2012) and http://www.guardian.co.uk/ world/2009/sep/12/dancing-boys-afghanistan (retreived 22th June 2012).

${ }^{5}$ In medical ethics, four main ethical principles have been found to be a common ethical ground to judge by in ethically challenging situations. A prima facie duty is meant to work as moral reassurance that no action is taken that is based too much on intuition and subjective opinion. The four prima facie duties in medical ethics are to be balanced against each other in concrete situations, and even if one or the other of them may be given more weight in the final judgment, it does not mean that the other duties are set aside. They still are just as important, and still should leave 'moral traces' (Ruyter, Førde, \& Solbakk, 2007). These principles are: 1) respect for autonomy - a norm concerning respect for autonomous persons' ability to make judgments, 2) non-injury - a norm meant to prevent injury, 3) beneficence - a group of norms to balance utility against risks and costs and 4) justice - a group of norms to spread out utility, risks and costs in a good way (Ruyter et al. 2007: 36, translation by author)

${ }^{6}$ If we read the Norwegian Armed Forces' home pages, the wording of the mission in Afghanistan has changed accordingly over the years. Earlier, part of the mission was to 'protect the Afghan people.' This wording has been removed and replaced by a sentence explaining that ISAF forces are to build up Afghan Security Forces so that they can protect the Afghan people (www.forsvaret.no, 29.01.14), which reflects the stronger focus on the task of mentoring Afghan security forces. During the last years of the ISAF contribution, which ended in 2014, conducting mentor programs for Afghan security forces became the main task.

${ }^{7}$ It is nevertheless a fact that Afghan authorities fail to enforce this law. Even representatives of Afghan authorities, like security officials, take part in the practice of 'bacha bazi'. The American case referred to in this article is about such an instance (Goldstein, 2015).

${ }^{8}$ Look for example to the movie Armadillo and Carsten Jensen's novel The first stone as two fairly recent works illustrating my point about the risk of demoralization. (Jensen 2016; Pedersen 2010)

\section{References}

Addis, A. (1997). On Human Diversity and the Limits of Toleration. In I. S. W. Kymlicka (Ed.), Ethnicity and Group Rights. NOMOS XXXIX (pp. 112-154). New York and London: New York University Press.

Beauchamp, T. L. C., J.F. (1994). Principles of biomedical ethics (4 ed.). Oxford University Press. 
Bird, C. (2004). Status, Identity and Respect. Political Theory, 32(2), 207-232. https://doi.org/10.1177/0090591703256686

Darwall, S. L. (1977). Two kinds of respect. Ethics, 88(1), 207-232. https://doi.org/10.1086/292054

Dillon, R. S. (2015). Respect. The Stanford Encyclopedia of Philosophy. Last retrieved 20.11.17 from https://plato.stanford.edu/archives/fall2015/entries/respect/

Forsvaret. (2011). Forsvarets verdigrunnlag. Oslo.

Forsvaret. (2015a). Forsvarets verdigrunnlag. Last retrieved 20.11 .17 from https://forsvaret.no/fakta/historie-oppdrag-verdier/forsvaretsverdiar/forsvarets-verdigrunnlag

Forsvaret. (2015b). Values and Standards. Last retrieved 20.11.17 from https://forsvaret.no/en/facts/uniforms-and-medals/values

Goldstein, J. (2015). U.S. Soldiers Told to Ignore Sexual Abuse of Boys by Afghan Allies. The New York Times. Last retrieved 20.11.17 from http://www.nytimes.com/2015/09/21/world/asia/us-soldiers-told-to-ignoreafghan-allies-abuse-of-boys.html?_r=0

ICRC. (2016, 12.12.2016). War \& Law. Last retrieved 20.11 .17 from https://www.icrc.org/en/war-and-law

Ingierd, H. C. (2007). The Moral Responsibility and Culpability of Peacekeepers - an Analysis of the Responsibility to Protect in Peace Support Operations. Paper presented at the Fagkonferansen i statsvitenskap Trondheim. Paper last retrieved 20.11.17 from http://webcache.googleusercontent.com/search? q=cache:G845EcoKBAoJ:www.svt.ntnu.no/iss/fagkonferanse2007/intern/pa pers/helene\%40prio.noDilemma\%2520of\%2520protection.doc $+\& \mathrm{~cd}=1 \& \mathrm{hl}=$ no\&ct $=\mathrm{clnk} \& \mathrm{gl}=$ no

Ingierd, H. C., \& Syse, H. (2005). Responsibility and Culpability in War. Journal of Military Ethics, 4(2), 85-99. http://dx.doi.org/10.1080/15027570510030798

Jensen, C. (2016). Den første sten (H. Syvertsen, Trans.): Forlaget Press.

Khomyakov, M. (2013). Toleration and respect: Historical instances and current problems. European Journal of Political Theory, 12(3), 223-239. https://doi.org/10.1177/1474885112465247

Kukhatas, C. (1997). Cultural toleration. In I. K. Shapiro, Will (Ed.), Ethnicity and Group Rights. NOMOS XXXIX (pp. 69-105). New York and London: New York University Press.

Maguen, S., \& Litz, B. (2012). Moral Injury in Veterans of War. Retrieved 2016 and 20.11.17 from National Center for PTSD http://www.ptsd.va.gov

Pedersen, J. M. (Writer). (2010). Armadillo. In F. Film (Producer).

Ross, W. D. (1930). The right and the good. London: Oxford University Press.

Ruyter, K. W., Førde, R., \& Solbakk, J. H. (2007). Medisinsk og helsefaglig etikk (2 ed.): Gyldendal Akademisk.

Schulzke, M. (2013). Ethically Insoluble Dilemmas in War. Journal of Military Ethics, 12(2), 95-110. https://doi.org/10.1080/15027570.2013.818406

Taylor, C. (1994). The Politics of Recognition. In A. Gutmann (Ed.), Multiculturalism (pp. 25-75). Princeton New Jersey: Princeton University Press.

Trettenes, H. (2009). Militormakt i komplekse konflikter - sjefens trening og hans praksis $i$ Afghanistan. Er treningen hjemme relevant for beslutningstakere $i$ 
Afghanistan? (Master thesis, Forsvarets høgskole, Forsvarets stabsskole) Oslo, Forsvarets høgskole.

UN Declaration on Human Rights, (1948).

The United Nations Convention on the Rights of the Child, United Nations (United Nations 1989).

Vikan, C. (2009). Etikk i gråsonen mellom krig og fred. En undersøkelse av Norges engasjement i Afghanistan. (Master thesis, Universitetet i Tromsø) Tromsø, Universitetet i Tromsø. 